\title{
Divergent Significance of Bone Mineral Density Changes in Aging Depending on Sites and Sex Revealed through Separate Analyses of Bone Mineral Content and Area
}

\author{
Yasumoto Matsui, ${ }^{1}$ Marie Takemura, ${ }^{1}$ Atsushi Harada, ${ }^{1}$ Fujiko Ando, ${ }^{2,3}$ \\ and Hiroshi Shimokata ${ }^{3}$ \\ ${ }^{1}$ Department of Orthopedic Surgery, National Center for Geriatrics and Gerontology, 35 Gengo, Morioka-cho, Obu 474-8511, Japan \\ ${ }^{2}$ Department of Health and Medical Sciences, Aichi Shukutoku University, Nagoya 464-8671, Japan \\ ${ }^{3}$ Department for Development of Preventive Medicine, Center for Development of Advanced Medicine for Dementia, \\ National Center for Geriatrics and Gerontology, Obu 474-8511, Japan
}

Correspondence should be addressed to Yasumoto Matsui, matsui@ncgg.go.jp

Received 15 June 2012; Revised 27 August 2012; Accepted 24 September 2012

Academic Editor: Harri Sievänen

Copyright (C) 2012 Yasumoto Matsui et al. This is an open access article distributed under the Creative Commons Attribution License, which permits unrestricted use, distribution, and reproduction in any medium, provided the original work is properly cited.

Bone mineral density (aBMD) is equivalent to bone mineral content (BMC) divided by area. We rechecked the significance of aBMD changes in aging by examining BMC and area separately. Subjects were 1167 community-dwelling Japanese men and women, aged 40-79 years. ABMDs of femoral neck and lumbar spine were assessed by DXA twice, at 6-year intervals. The change rates of BMC and area, as well as aBMD, were calculated and described separately by the age stratum and by sex. In the femoral neck region, aBMDs were significantly decreased in all age strata by an increase in area as well as BMC loss in the same pattern in both sexes. In the lumbar spine region, aBMDs decreased until the age of 60 in women, caused by the significant BMC decrease accompanying the small area change. Very differently in men, aBMDs increased after their 50s due to BMC increase, accompanied by an area increase. Separate analyses of BMC and area change revealed that the significance of aBMD changes in aging was very divergent among sites and between sexes. This may explain in part the dissociation of aBMD change and bone strength, suggesting that we should be more cautious when interpreting the meaning of aBMD change.

\section{Introduction}

Bone mineral density (aBMD) decreases with age [1] and it is the most significant and widely used index for the diagnosis of osteoporosis and for considering the effects of medication in its treatment [2]. When an aBMD decrease is found, the cause is usually considered to be a decrease in bone mineral content (BMC) in the region measured. $\mathrm{ABMD}$ is equivalent to BMC divided by an area. Since areal BMD depends both on bone mineral content and bone dimensions, it is difficult to interpret unambiguously [3]. Dimensional changes occur in long bone by aging [4-6], the shape of the bone, and conditions like osteophytes or vertebral fracture in lumbar spine [7-9] are well known. These can affect the measuring area of DXA examinations, and naturally their results. However, a longitudinal epidemiological DXA study on aging considering the effect of the area has not been carried out on a large scale, although there have been crosssectional studies [10-17]. This study was performed in order to reconsider the significance of aBMD change and aging in different anatomical locations, by analyzing the longitudinal changes of both components of aBMD, namely, BMC and the area, and comparing the differences in sex. A large cohort for longitudinal studies of local inhabitants was used for this study.

\section{Materials and Methods}

2.1. Subjects. The subjects were selected among people who participated in both the 1st and 4th waves of the National Institute for Longevity Sciences Longitudinal Study 
of Aging (NILS-LSA). Details of the NILS-LSA are presented elsewhere [18]. It is a biannual examination checking the physical and mental condition of ordinary Japanese people, so as to clarify the effect of aging. It is conducted by the National Center for Geriatrics and Gerontology (NCGG), in Japan. The National Institute for Longevity Sciences (NILS) is a research section of NCGG. The participants were chosen randomly from the residents of Obu city and Higashiuracho, in Aichi prefecture, Japan. For this study, data from 1167 persons were analyzed $(59.2 \pm 10.9$, mean \pm SD). Participants were 594 men and 573 women, whose ages ranged from 40 to 79 at the time of the 1 st wave. The 1 st and 4 th waves were from November 1997 to April 2000, and June 2004 to July 2006, respectively.

2.2. Measurements of Bone Mineral Density. Areal bone mineral densities (aBMD) were measured using Hologic QDR4500, both at the 1st and 4th wave. Only one DXA scanner was used. Data on the right femoral neck (Figure 1) and the lumbar spine (L2-4) were used for the analysis. Coefficients of variance of the DXA instrument for aBMD were $1.3 \%$ (femoral neck), 1.0\% (trochanter), and 0.9\% (L2,1-4) [19]. ABMD is equivalent to BMC divided by an area, so the following formula was used for the theoretical calculation: $\operatorname{aBMD}\left(\mathrm{g} / \mathrm{cm}^{2}\right)=$ BMC $(\mathrm{g}) /$ Area $\left(\mathrm{cm}^{2}\right)$. Therefore, not only $\mathrm{aBMD}$ values but also those of BMC and the area measured were used for the analysis in the three different regions above. The annual change rates (CR) were calculated by the following formula. CR $(\%)=$ (the values in the 4 th-the values in the 1 st)/the values in the 1 st $\times 100 / 6$. The CRs of aBMD, BMC, and the area measured were calculated and described separately by the age stratum of $40 \mathrm{~s}, 50 \mathrm{~s}, 60 \mathrm{~s}$, and 70 s and by sex. All who were 40 to 49 years at baseline belonged to the 40's age stratum, and so forth. Data are presented as the mean $\pm \mathrm{SD}$, including those in figures. The study protocol was approved by the Committee on Ethics of Human Research of the National Institute for Longevity Sciences. Written informed consent was obtained from each subject.

2.3. Statistical Analyses. The statistical analyses were made to test for significance of change (versus no change) in each subgroup defined by age decade and sex, using paired $t$-tests. Also, the trend analyses according to the increase of the age stratum were made for each subgroup using a general linear model procedure. Gender difference was checked for each subgroup. All analyses were conducted using SAS Ver. 8.2 (SAS Institute, Cary, NC, USA).

\section{Results}

Characteristics of subjects were shown in Table 1.

The change rates (CR) from the first to fourth what were expressed as an annual rate. Mean variation between the two DXA measurements was 6 years.

3.1. Femoral Neck Region. ABMDs significantly decreased in all age strata both in women $(-1.1 \pm 1.1 \%$ in $40 \mathrm{~s},-1.2 \pm 0.9 \%$

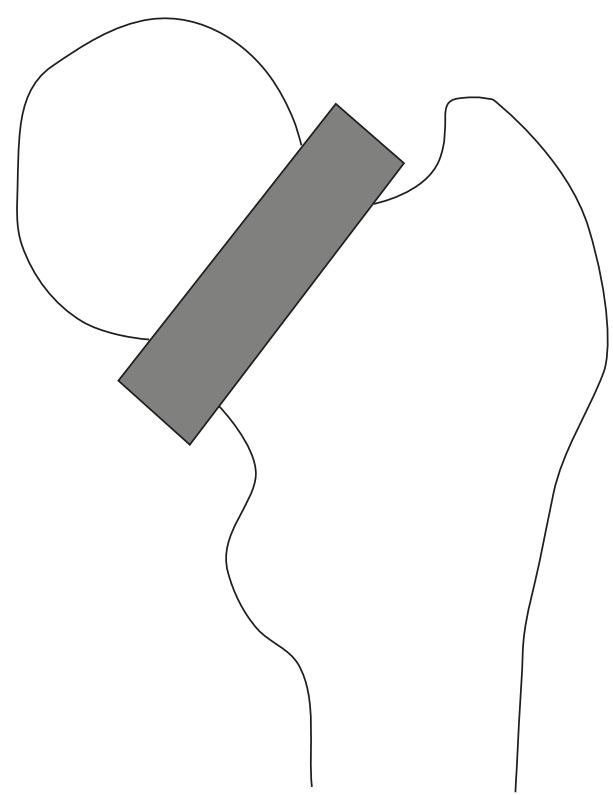

FIGURE 1: Femoral neck region of interest, derived from the Hologic QDR 4500 Operator's Manual.

in $50 \mathrm{~s},-1.0 \pm 0.9 \%$ in $60 \mathrm{~s}$, and $-0.8 \pm 1.1 \%$ in $70 \mathrm{~s}$, all $P<0.01)$ and in men $(-0.4 \pm 0.8 \%$ in 40 s, $-0.5 \pm 0.7 \%$ in $50 \mathrm{~s},-0.6 \pm 0.9 \%$ in $60 \mathrm{~s}$, and $-0.6 \pm 1.0 \%$ in $70 \mathrm{~s}$, all $P<0.01$ ) (Figures 2(a) and 2(b)). These declines were caused not merely by the decrease of BMC in most of the age strata (in women, $-0.7 \pm 1.4 \%$ in $40 \mathrm{~s},-0.8 \pm 1.2 \%$ in $50 \mathrm{~s}$, and $-0.4 \pm 1.2 \%$ in $60 \mathrm{~s}$, all $P<0.01$, and in men, $-0.2 \pm 0.9 \%$ in 50s and $-0.2 \pm 1.1 \%$ in 70 s, with $P<0.01$ and $P<0.05$, resp.), but also by the constant or significant increase of the area measured (in women, $0.4 \pm 1.1 \%$ in $40 \mathrm{~s}, 0.5 \pm 1.1 \%$ in 50 s, $0.6 \pm 1.2 \%$ in 60 s, and $0.5 \pm 1.5 \%$ in 70 s, all $P<0.01$, and in men, $0.4 \pm 0.6 \%$ in $40 \mathrm{~s}, 0.3 \pm 0.8 \%$ in $50 \mathrm{~s}, 0.4 \pm 0.8 \%$ in $60 \mathrm{~s}$, and in $0.4 \pm 0.8 \%$ in $70 \mathrm{~s}$, all $P<0.01)$. This trend was the same in both sexes. The change rates (CR) of the aBMD and BMC, however, were different between women and men in their 40s, 50s, and 60s (Table 2). The CR became higher (in absolute value) only in women according to age in aBMD and BMC ( $P$ trend $=0.0126$ and 0.0027 , resp.). As for the CR of the area, no significant trend according to age was observed in both sexes, and no sex difference was observed (Table 2).

3.2. Lumbar Spine Region. ABMDs significantly decreased in women in their $40 \mathrm{~s}, 50 \mathrm{~s}$, and $60 \mathrm{~s}(-1.1 \pm 1.2 \%$ in $40 \mathrm{~s}$, $-1.0 \pm 0.9 \%$ in $50 \mathrm{~s}$, and $-0.2 \pm 1.1$ in $60 \mathrm{~s}$, with $P<0.01$, $P<0.01$ and $P<0.05$, resp.) (Figure 3(a)). At earlier ages, these declines were caused by a significant decrease in BMC $(-1.2 \pm 1.5 \%$ in $40 \mathrm{~s}$ and $-1.2 \pm 1.2 \%$ in $50 \mathrm{~s}$, both $P<$ 0.01 ) accompanied by a small but significant decrease in the area. After their 60s, however, no further decrease in BMC occurred, and the small but significant increase of aBMD was caused by the significant increase in the area.

The patterns of aBMD changes were much different in men. BMDs significantly increased in the $50 \mathrm{~s}, 60 \mathrm{~s}$, and $70 \mathrm{~s}$ $(0.3 \pm 0.8 \%, 0.5 \pm 1.5 \%$, and $0.3 \pm 1.0 \%$, all $P<0.01)$ due to 


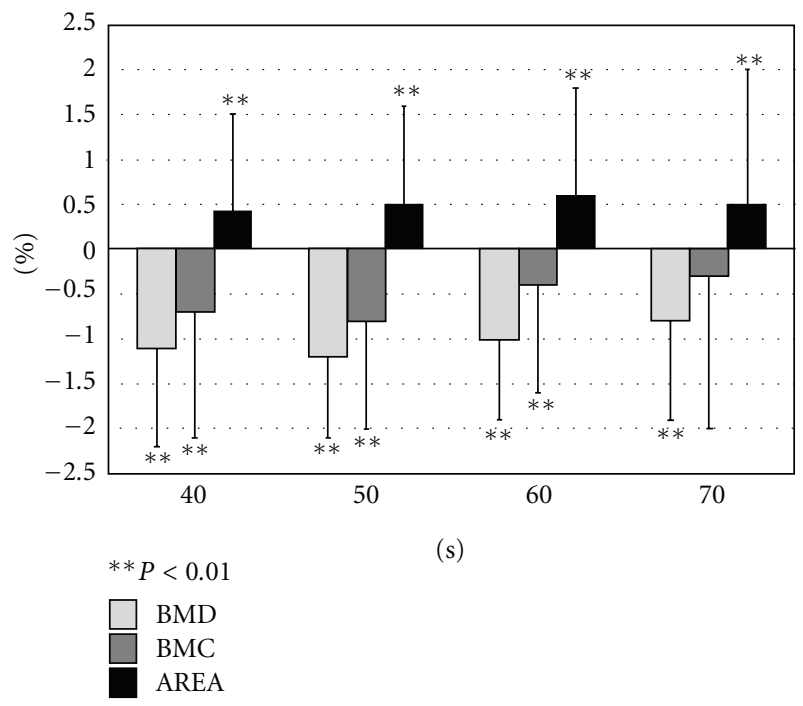

(a)

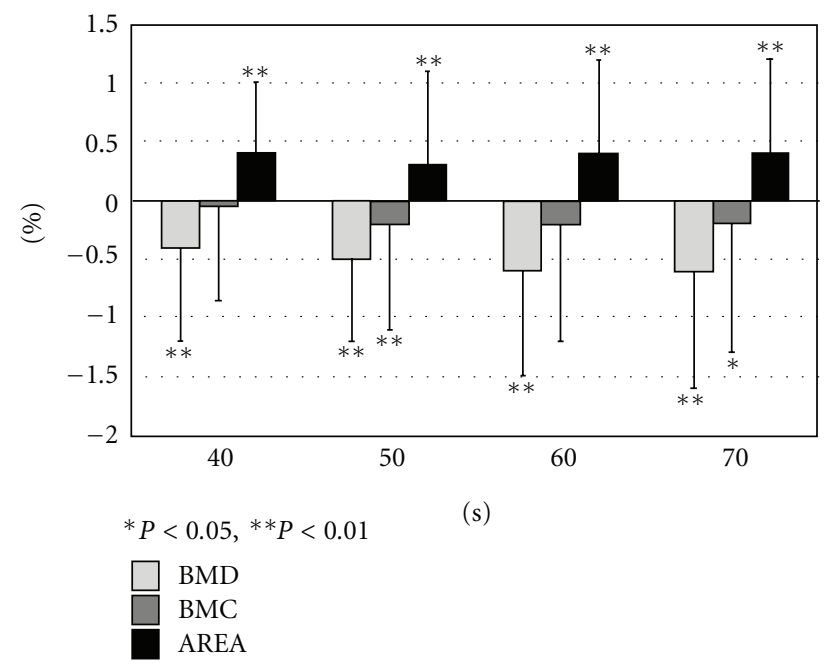

(b)

FIGURE 2: (a) Changes in the femoral neck region by age group in women. Results are the mean $( \pm S D)$ CR of four different age strata. ${ }^{* *} P<0.01$. (b) Changes in the femoral neck region by age group in men. Results are the mean $( \pm \mathrm{SD}) \mathrm{CR}$ of four different age strata. ${ }^{*} P<0.05,{ }^{* *} P<0.01$.

the significant increase of BMC $(0.5 \pm 1.0 \%$ in $50 \mathrm{~s}, 1.0 \pm 3.4 \%$ in 60 s, and $0.4 \pm 1.2 \%$ in 70 s, all $P<0.01$ ) (Figure $3(\mathrm{~b})$ ). The areas significantly increased in every age stratum $(0.1 \pm 0.5 \%$ in $40 \mathrm{~s}, 0.2 \pm 0.5 \%$ in $50 \mathrm{~s}, 0.4 \pm 1.2 \%$ in $60 \mathrm{~s}$, and $0.2 \pm 0.6 \%$ in 70s, all $P<0.01$ ). Since the increase of BMD occurred after the 50s, the rates of BMC increase surpassed those of the area. The change rates $(\mathrm{CR})$ of the $\mathrm{BMD}, \mathrm{BMC}$, and area were different between women and men in their 40s, 50s, and 60s (Table 2). And in women the CR increased according to age in aBMD, BMC, and area $(P$ trend $<0.0001, P$ trend $<0.0001$, and $P$ trend $=0.0115$, resp. $)$. The CR increased in men according to age in aBMD and BMC $(P$ trend $=0.006$ and $P$ trend $=0.027$, resp.), but not in area (Table 2$)$.

TABLE 1: Characteristics of subjects.

\begin{tabular}{ccc}
\hline & Women & Men \\
\hline Age (years) & $56.5 \pm 9.9$ & $57.9 \pm 9.9$ \\
Height $(\mathrm{cm})$ & & \\
All & $152.2 \pm 5.7$ & $165.4 \pm 5.9$ \\
& $(n=573)$ & $(n=594)$ \\
$40 \mathrm{~s}$ & $154.9 \pm 5.0$ & $168.7 \pm 5.5$ \\
& $(n=168)$ & $(n=148)$ \\
$50 \mathrm{~s}$ & $153.3 \pm 4.8$ & $166.3 \pm 5.7$ \\
& $(n=179)$ & $(n=183)$ \\
$60 \mathrm{~s}$ & $150.4 \pm 5.6$ & $164.0 \pm 4.7$ \\
& $(n=147)$ & $(n=162)$ \\
$70 \mathrm{~s}$ & $147.0 \pm 5.0$ & $161.0 \pm 5.2$ \\
& $(n=79)$ & $(n=101)$
\end{tabular}

Weight (kg)

All

40 s

50 s

$60 s$

70 s

BMI $\left(\mathrm{kg} / \mathrm{m}^{2}\right)$

All

40 s

50 s

60 s

70 s

BMD at 1 st wave

Femoral neck $\left(\mathrm{g} / \mathrm{cm}^{2}\right)$

Trochanter $\left(\mathrm{g} / \mathrm{cm}^{2}\right)$

Lumbar spine (L2-4) $\left(\mathrm{g} / \mathrm{cm}^{2}\right)$

$\mathrm{BMC}$ at 1 st wave

Femoral neck (g)

Trochanter $(\mathrm{g})$

Lumbar spine (L2-4) (g)

Area at 1 st wave

Femoral neck $\left(\mathrm{cm}^{2}\right)$

Trochanter $\left(\mathrm{cm}^{2}\right)$

Lumbar spine (L2-4) $\left(\mathrm{cm}^{2}\right)$

Values are mean $\pm \mathrm{SD}$.

\section{Discussion}

$\mathrm{ABMD}$ is equivalent to BMC divided by an area, but when we encounter cases of BMD decline, we simply consider the decline of the $\mathrm{BMC}$ at the measured sites without

$$
\begin{array}{cc}
53.0 \pm 8.0 & 62.8 \pm 8.5 \\
(n=573) & (n=594) \\
54.1 \pm 8.0 & 66.4 \pm 8.8 \\
(n=168) & (n=148) \\
53.7 \pm 7.4 & 63.5 \pm 8.1 \\
(n=179) & (n=183) \\
53.0 \pm 8.0 & 61.2 \pm 7.8 \\
(n=147) & (n=162) \\
49.1 \pm 7.9 & 58.8 \pm 7.5 \\
(n=79) & (n=101)
\end{array}
$$$$
\begin{array}{cc}
22.9 \pm 3.2 & 22.9 \pm 2.6 \\
(n=573) & (n=594) \\
22.5 \pm 3.3 & 23.3 \pm 2.6 \\
(n=168) & (n=148) \\
22.9 \pm 3.2 & 23.0 \pm 2.5 \\
(n=179) & (n=183) \\
23.4 \pm 3.1 & 22.8 \pm 2.7 \\
(n=147) & (n=162) \\
22.7 \pm 3.1 & 22.6 \pm 2.5 \\
(n=79) & (n=101)
\end{array}
$$$$
0.7 \pm 0.1 \quad 0.8 \pm 0.1
$$$$
0.6 \pm 0.1 \quad 0.7 \pm 0.1
$$$$
0.9 \pm 0.2 \quad 1.0 \pm 0.2
$$

$$
\begin{array}{cc}
3.2 \pm 0.6 & 4.0 \pm 0.7 \\
6.0 \pm 1.3 & 8.7 \pm 1.6 \\
38.1 \pm 9.3 & 50.7 \pm 10.0
\end{array}
$$

$\begin{array}{cc}4.6 \pm 0.3 & 5.3 \pm 0.3 \\ 10.2 \pm 1.2 & 12.8 \pm 1.4 \\ 42.3 \pm 3.9 & 51.3 \pm 4.5\end{array}$


TABle 2: $P$ trend according to age strata and $P$ value of sex difference analyses of subgroup.

\begin{tabular}{|c|c|c|c|c|c|c|c|}
\hline & & \multicolumn{2}{|c|}{$P$ trend according to age strata } & \multicolumn{4}{|c|}{ Sex difference analysis } \\
\hline & & women & men & $40 \mathrm{~s}$ & $50 \mathrm{~s}$ & $60 \mathrm{~s}$ & $70 \mathrm{~s}$ \\
\hline \multirow{3}{*}{ Femoral neck } & $\mathrm{BMD}$ & 0.0126 & 0.1682 & $<0.0001$ & $<0.0001$ & $<0.0001$ & 0.0982 \\
\hline & $\mathrm{BMC}$ & 0.0027 & 0.2519 & $<0.0001$ & $<0.0001$ & 0.0298 & 0.7122 \\
\hline & Area & 0.2084 & 0.9947 & 0.9436 & 0.0434 & 0.0987 & 0.2391 \\
\hline \multirow{3}{*}{ Lumbar spine } & BMD & $<0.0001$ & 0.006 & $<0.0001$ & $<0.0001$ & $<0.0001$ & 0.815 \\
\hline & $\mathrm{BMC}$ & $<0.0001$ & 0.027 & $<0.0001$ & $<0.0001$ & $<0.0001$ & 0.4277 \\
\hline & Area & 0.0115 & 0.3383 & $<0.0001$ & $<0.0001$ & 0.0052 & 0.0986 \\
\hline
\end{tabular}

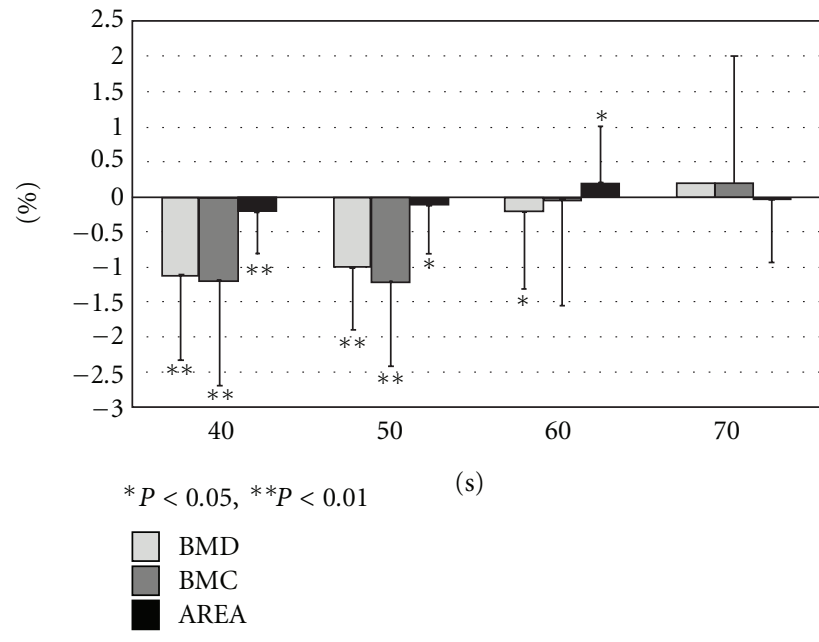

(a)

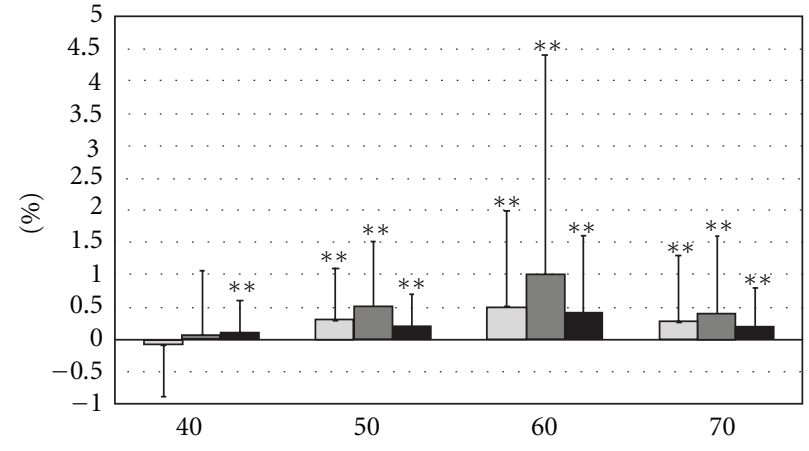

(s)

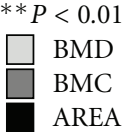

(b)

Figure 3: (a) Changes in the lumbar spine region by age group in women. Results are the mean $( \pm S D)$ CR of four different age strata. ${ }^{*} P<0.05,{ }^{* *} P<0.01$. (b) Changes in the lumbar spine region by age group in men. Results are the mean $( \pm \mathrm{SD})$ CR of four different age strata. ${ }^{* *} P<0.01$.

incorporating the change of the area (or size), which may represent the change of the shape in the region. The present study demonstrated that in the femoral neck, the aBMD decline in aging occurs not only due to the decline of BMC, but also due to the increase in the area, for both men and women. In fact, the increase of the femoral neck area represents the physiological compensating effect of the weakened bone tolerance $[4,20-23]$, caused by BMC decline. This may be one of the reasons for the dissociation between the strength of the bone and aBMD values. The widening (or enlargement) of the femoral neck in elderly persons has been demonstrated by the hip structure analyses of DXA [10, 13-15], by computed tomography [23-26], or utilizing both $[27,28]$. The annual change rates of aBMD in our study in the femoral neck region were around $-1 \%$ in women (Figure 2(a)) and $0.5 \%$ in men (Figure 2(b)). This is almost equal to the level of the large populationbased cohort in Hiroshima Japan, $-1.14 \%$ in women, and $-0.38 \%$ in men [29]. In the lumbar spine, however, a sexual difference was observed in the changes of aBMD and those of BMC or the area as well. The increase in BMC together with the area may be explained by the osteophyte formation found to be more marked in elderly men $[7,9]$. This type of change, osteophyte formation, occurs also in women but later. The significant area increase in women may derive from the osteophyte formation in advanced age. The reason for the significant decrease in the areas in women in their 40s and 50s is unclear at the moment. More detailed studies, using CT scans, are warranted to elucidate the mechanism of the sex difference in the spinal region.

From this perspective, the meaning or significance of aBMD change should be diverse depending on the sites measured and gender. Moreover, the apparent decrease of aBMD may not simply represent the weakness of that measured region (e.g., in the femoral neck), since the greater diameter can make the cylindrical structure stronger [21].

The limitation of this study is that the measurements were carried out by the ordinary DXA method without using elaborate software like hip structure analysis or CT. DXA has an inherent inaccuracy [30-32]. If body composition or weight changed during the followup, it is possible that BMD is inaccurately measured, namely, it may be overor underestimated. Also, the size measuring by DXA was not very accurate for volumetric analysis. But our method disclosed the differences among sites and between sexes, particularly in terms of longitudinal effect, which have been little investigated. 
The strength of our study is its random selection of our samples from people in the local community with very little bias in the process. NILS-LSA is one of the few major epidemiological studies investigating the aging mechanism that is designed to select subjects in a completely random manner. The results of this study should therefore reveal characteristics of the entire Japanese population.

In summary, we investigated the meaning of aBMD changes in aging through separate analyses of BMC and area change. The results revealed that the significance of aBMD changes were very divergent among the sites measured, and between sexes. This may explain the dissociation of aBMD change and bone strength, which encourages one to be more cautious when interpreting the meaning of aBMD change.

\section{Acknowledgment}

This work was supported by the research fund for Longevity Sciences [23-33] from the National Center for Geriatrics and Gerontology (NCGG), Japan.

\section{References}

[1] P. Steiger, S. R. Cummings, D. M. Black, N. E. Spencer, and H. K. Genant, "Age-related decrements in bone mineral density in women over 65," Journal of Bone and Mineral Research, vol. 7, no. 6, pp. 625-632, 1992.

[2] S. R. Cummings, D. Bates, and D. M. Black, "Clinical use of bone densitometry: scientific review," Journal of the American Medical Association, vol. 288, no. 15, pp. 1889-1897, 2002.

[3] H. Sievänen, "A physical model for dual-energy X-ray absorptiometry-derived bone mineral density," Investigative Radiology, vol. 35, no. 5, pp. 325-330, 2000.

[4] C. B. Ruff and W. C. Hayes, "Subperiosteal expansion and cortical remodeling of the human femur and tibia with aging," Science, vol. 217, no. 4563, pp. 945-948, 1982.

[5] R. P. Heaney, M. J. Barger-Lux, K. M. Davies, R. A. Ryan, M. L. Johnson, and G. Gong, "Bone dimensional change with age: interactions of genetic, hormonal, and body size variables," Osteoporosis International, vol. 7, no. 5, pp. 426-431, 1997.

[6] H. G. Ahlborg, O. Johnell, C. H. Turner, G. Rannevik, and M. K. Karlsson, "Bone loss and bone size after menopause," New England Journal of Medicine, vol. 349, no. 4, pp. 327-334, 2003.

[7] H. Kinoshita, T. Tamaki, T. Hashimoto, and F. Kasagi, "Factors influencing lumbar spine bone mineral density assessment by dual-energy X-ray absorptiometry: comparison with lumbar spinal radiogram," Journal of Orthopaedic Science, vol. 3, no. 1, pp. 3-9, 1998.

[8] A. Atalay, M. Kozakcioglu, R. Cubuk, N. Tasali, and S. Guney, "Degeneration of the lumbar spine and dual-energy X-ray absorptiometry measurements in patients without osteoporosis," Clinical Imaging, vol. 33, no. 5, pp. 374-378, 2009.

[9] Ö Karabulut, M. C. Tuncer, Z. Karabulut, A. Açlkgöz, E. S. Hatipoğlu, and Z. Akkuş, "Relationship between radiographic features and bone mineral density in elderly men," Folia Morphologica, vol. 69, no. 3, pp. 170-176, 2010.

[10] T. J. Beck, C. B. Ruff, W. W. Scott Jr., C. C. Plato, J. D. Tobin, and C. A. Quan, "Sex differences in geometry of the femoral neck with aging: a structural analysis of bone mineral data," Calcified Tissue International, vol. 50, no. 1, pp. 24-29, 1992.
[11] K. S. Tsai, W. C. Cheng, C. K. Chen et al., "Effect of bone area on spine density in Chinese men and women in Taiwan," Bone, vol. 21, no. 6, pp. 547-551, 1997.

[12] M. Peacock, G. Liu, M. Carey et al., "Bone mass and structure at the hip in men and women over the age of 60 years," Osteoporosis International, vol. 8, no. 3, pp. 231-239, 1998.

[13] T. J. Beck, A. C. Looker, C. B. Ruff, H. Sievanen, and H. W. Wahner, "Structural trends in the aging femoral neck and proximal shaft: analysis of the Third National Health and Nutrition Examination Survey dual-energy x-ray absorptiometry data," Journal of Bone and Mineral Research, vol. 15, no. 12, pp. 2297-2304, 2000.

[14] S. Kaptoge, N. Dalzell, N. Loveridge, T. J. Beck, K. T. Khaw, and J. Reeve, "Effects of gender, anthropometric variables, and aging on the evolution of hip strength in men and women aged over 65," Bone, vol. 32, no. 5, pp. 561-570, 2003.

[15] D. A. Nelson, J. M. Pettifor, D. A. Barondess, D. D. Cody, K. Uusi-Rasi, and T. J. Beck, "Comparison of cross-sectional geometry of the proximal femur in white and black women from Detroit and Johannesburg," Journal of Bone and Mineral Research, vol. 19, no. 4, pp. 560-565, 2004.

[16] X. F. Wang, Y. Duan, T. J. Beck, and E. Seeman, "Varying contributions of growth and ageing to racial and sex differences in femoral neck structure and strength in old age," Bone, vol. 36, no. 6, pp. 978-986, 2005.

[17] A. C. Looker, H. W. Wahner, W. L. Dunn et al., "Updated data on proximal femur bone mineral levels of US adults," Osteoporosis International, vol. 8, no. 5, pp. 468-489, 1998.

[18] H. Shimokata, F. Ando, and N. Niino, "A new comprehensive study on aging - the National Institute for Longevity Sciences, Longitudinal Study of Aging (NILS-LSA)," Journal of Epidemiology, vol. 10, no. 1, pp. S1-S9, 2000.

[19] Y. Yamada, F. Ando, N. Niino, and H. Shimokata, "Association of polymorphisms of interleukin-6, osteocalcin, and vitamin $\mathrm{D}$ receptor genes, alone or in combination, with bone mineral density in community-dwelling Japanese women and men," Journal of Clinical Endocrinology and Metabolism, vol. 88, no. 7, pp. 3372-3378, 2003.

[20] B. Martin, "Aging and strength of bone as a structural material," Calcified Tissue International, vol. 53, supplement 1, pp. S34-S39, 1993.

[21] E. Seeman, "Periosteal bone formation-a neglected determinant of bone strength," New England Journal of Medicine, vol. 349 , no. 4, pp. 320-323, 2003.

[22] E. S. Orwoll, "Toward an expanded understanding of the role of the periosteum in skeletal health," Journal of Bone and Mineral Research, vol. 18, no. 6, pp. 949-954, 2003.

[23] C. R. Russo, F. Lauretani, E. Seeman et al., "Structural adaptations to bone loss in aging men and women," Bone, vol. 38, no. 1, pp. 112-118, 2006.

[24] T. F. Lang, J. H. Keyak, M. W. Heitz et al., "Volumetric quantitative computed tomography of the proximal femur: precision and relation to bone strength," Bone, vol. 21, no. 1, pp. 101108, 1997.

[25] B. L. Riggs, L. J. Melton III, R. A. Robb et al., "Populationbased study of age and sex differences in bone volumetric density, size, geometry, and structure at different skeletal sites," Journal of Bone and Mineral Research, vol. 19, no. 12, pp. 19451954, 2004.

[26] L. M. Marshall, T. F. Lang, L. C. Lambert, J. M. Zmuda, K. E. Ensrud, and E. S. Orwoll, "Dimensions and volumetric BMD of the proximal femur and their relation to age among older U.S. men," Journal of Bone and Mineral Research, vol. 21, no. 8, pp. 1197-1206, 2006. 
[27] J. S. Bauer, S. Kohlmann, F. Eckstein, D. Mueller, E. M. Lochmüller, and T. M. Link, "Structural analysis of trabecular bone of the proximal femur using multislice computed tomography: a comparison with dual X-ray absorptiometry for predicting biomechanical strength in vitro," Calcified Tissue International, vol. 78, no. 2, pp. 78-89, 2006.

[28] L. M. Havill, M. C. Mahaney, T. L. Binkley, and B. L. Specker, "Effects of genes, sex, age, and activity on BMC, bone size, and areal and volumetric BMD," Journal of Bone and Mineral Research, vol. 22, no. 5, pp. 737-746, 2007.

[29] N. Masunari, S. Fujiwara, Y. Nakata, K. Furukawa, and F. Kasagi, "Effect of angiotensin converting enzyme inhibitor and benzodiazepine intake on bone loss in older Japanese," Hiroshima Journal of Medical Sciences, vol. 57, no. 1, pp. 1725, 2008.

[30] J. M. P. Soriano, E. Ioannidou, J. Wang et al., "Pencil-beam versus fan-beam dual-energy X-ray absorptiometry comparisons across four systems: body composition and bone mineral," Journal of Clinical Densitometry, vol. 7, no. 3, pp. 281-289, 2004.

[31] H. H. Bolotin and H. Sievänen, "Inaccuracies inherent in dualenergy $\mathrm{x}$-ray absorptiometry in vivo bone mineral density can seriously mislead diagnostic/prognostic interpretations of patient-specific bone fragility," Journal of Bone and Mineral Research, vol. 16, no. 5, pp. 799-805, 2001.

[32] H. H. Bolotin, H. Sievänen, J. L. Grashuis, J. W. Kuiper, and T. L. N. Järvinen, "Inaccuracies inherent in patient-specific dualenergy X-ray absorptiometry bone mineral density measurements: Comprehensive phantom-based evaluation," Journal of Bone and Mineral Research, vol. 16, no. 2, pp. 417-426, 2001.

[33] H. H. Bolotin, H. Sievänen, and J. L. Grashuis, "Patientspecific DXA bone mineral density inaccuracies: quantitative effects of nonuniform extraosseous fat distributions," Journal of Bone and Mineral Research, vol. 18, no. 6, pp. 1020-1027, 2003. 


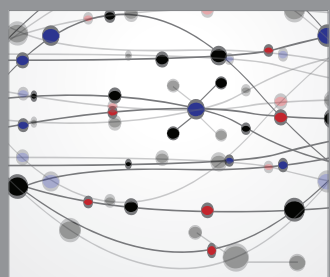

The Scientific World Journal
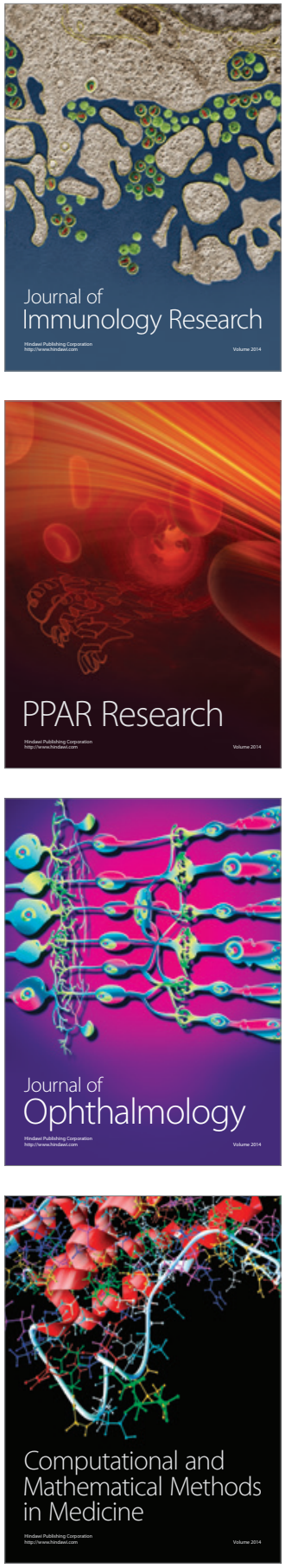

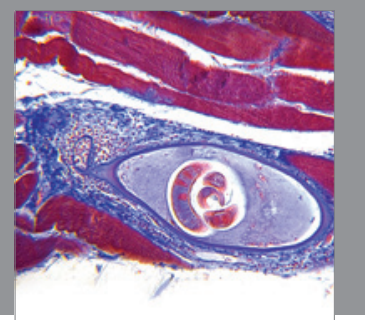

Gastroenterology

Research and Practice
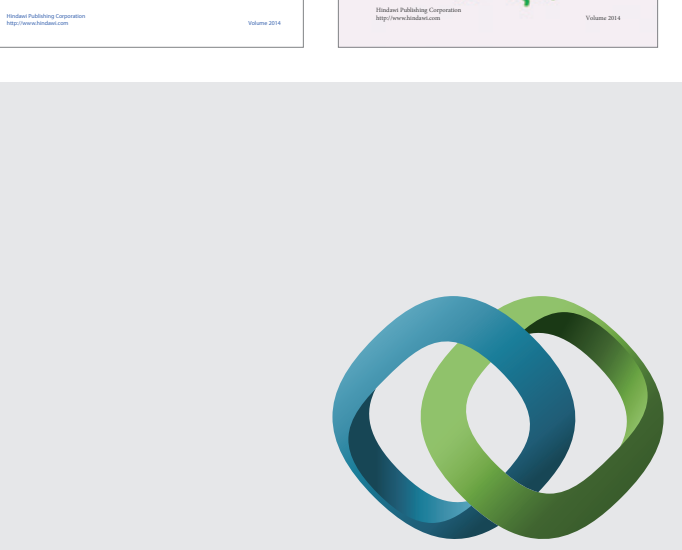

\section{Hindawi}

Submit your manuscripts at

http://www.hindawi.com
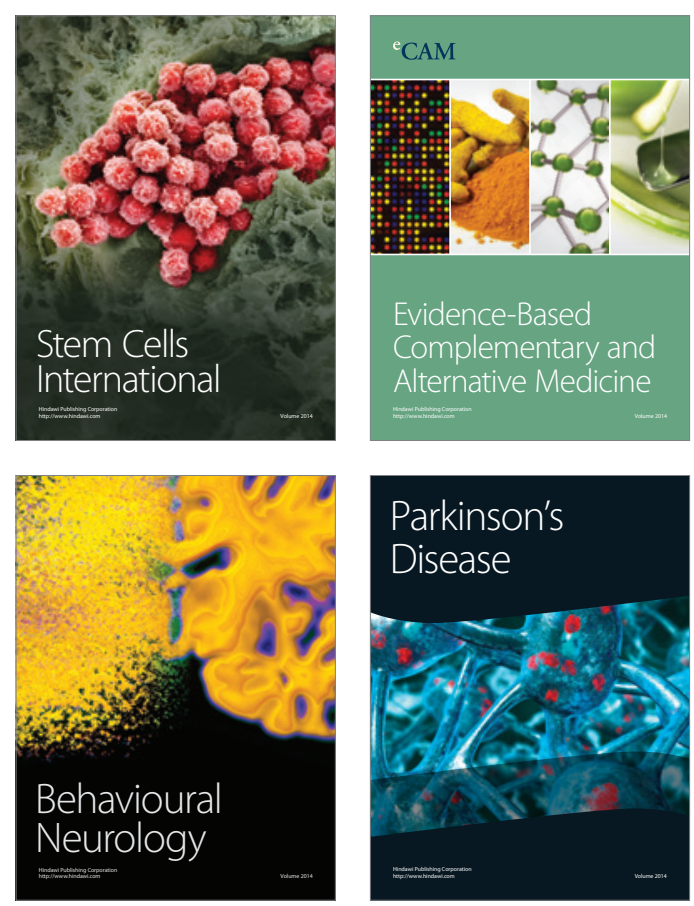

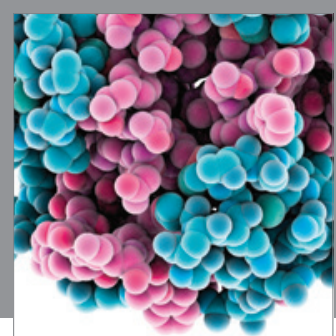

Journal of
Diabetes Research

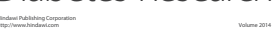

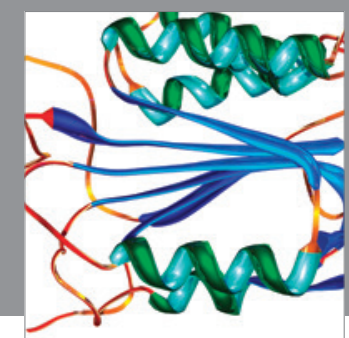

Disease Markers
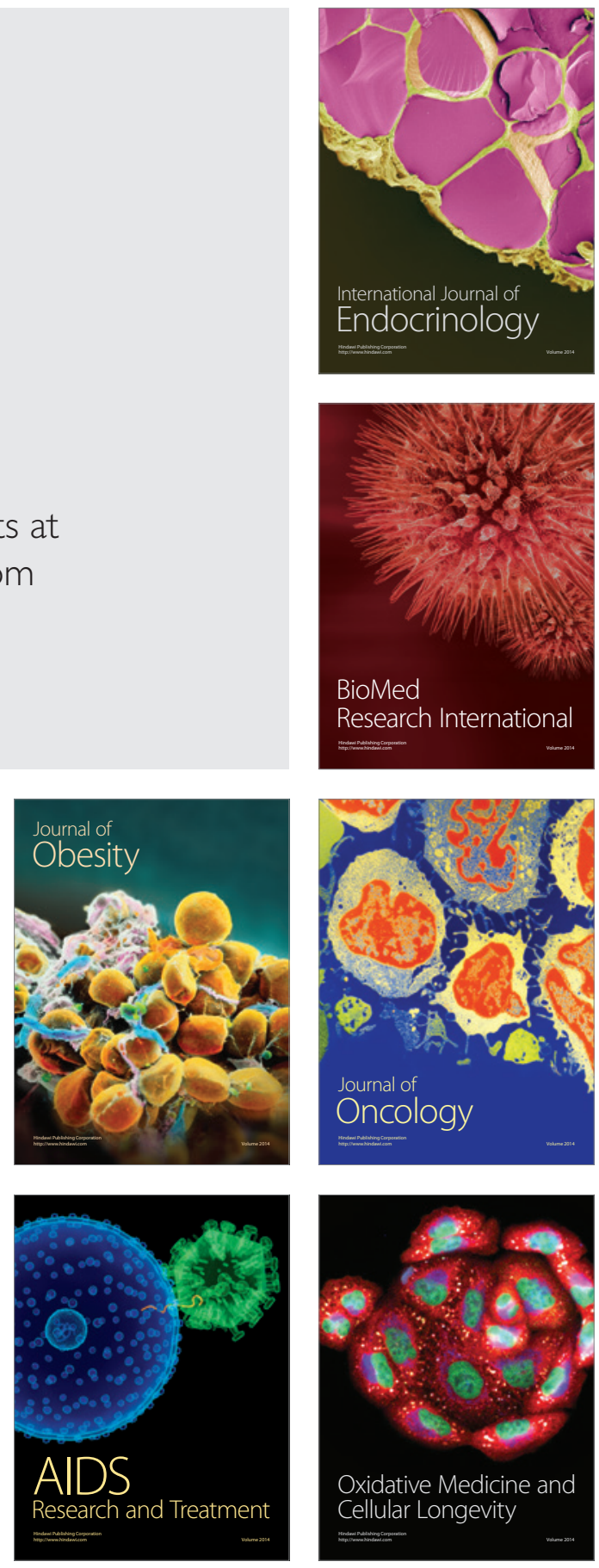